\title{
El chico que se echaba de menos
}

\author{
Pilar ORGILLÉS BOQUERA ${ }^{1}$ \\ pilar.orgilles@gmail.com
}

Recibido: $25 / 02 / 14$

Aceptado: 23/10/14

\section{RESUMEN}

A lo largo de los últimos 20 años, la disciplina del arteterapia se ha consolidado entre la comunidad terapéutica, adquiriendo una idiosincrasia y un procedimientos propios. Sin embargo, las formas del arteterapia permanecen todavía algo confusas, y en algunos casos estereotipadas, para el público no especializado. En este texto se realiza un abordaje práctico del arteterapia presentando el caso de un joven con problemas de adicción que sufre inesperadamente una castración corporal fruto de un accidente. El caso se inscribe entorno a una doble problemática, la creación de la imagen corporal propia y la construcción del sujeto narcisista. Durante su desarrollo se van descubriendo los elementos clave que conforman el proceso arteterapéutico, como la toma de contacto, el vínculo terapéutico, la comunicación mediada por las producciones artísticas o la importancia del cierre.

Palabras clave: Arteterapia, imagen corporal, narcisismo, esquema corporal, acompañamiento, adicción

\section{Referencia normalizada}

ORGILLÉS BOQUERA P. (2014). "El chico que se echaba de menos". En Arteterapia: Papeles de arteterapia y educación artística para la inclusión social Vol.: 9. Páginas 99-112. Madrid.

\section{SUMARIO}

Motivación. Antecedentes. Narración de un caso y su intervención desde el arteterapia. Referencias bibliográficas.

\section{The boy who missed himself}

\begin{abstract}
For the past twenty years the discipline of art-therapy has been consolidating amongst the therapeutic community, eventually acquiring its own idiosyncrasy and procedure. Nevertheless, the different ways of art-therapy are still barely understood, and sometimes seen through stereotypes, by non-specialists. In the present text a practical view of art-therapy is treated by exhibiting the case of a youngster with drug-addiction issues and a corporal castration resulting from an unexpected accident. The case revolves around a double

\footnotetext{
${ }^{1}$ Asociación GREFART
} 
predicament, namely, the formation of the self body image and the construction of the narcissist subject. Through its development the key elements of an art-therapeutic process are revealed, such as the initial contact, the therapeutic bond, the mediated communication through artistic creations or the importance of the closing.

Keywords: Art-therapy, body image, narcissism, anatomical chart, accompaniment, addiction.

\section{CONTENTS}

Motivation. Antecedents. Case account and art-therapy intervention. Bibliography references.

\section{Motivación}

Desde que en 1999 se inaugurara el primer máster oficial de arteterapia en Barcelona, la profesionalización de esta disciplina terapéutica en España ha experimentado un crecimiento sin precedentes (Domínguez, 2004). No obstante, el retraso de su oficialidad respecto a otros países como EUA o Gran Bretaña, donde lleva décadas consolidado, se hace evidente tanto en el escaso número de instituciones que le representan como en el difuso conocimiento que llega a la población, en forma de estereotipos y clichés prejuiciados.

En el presente artículo se pretende describir la práctica del arteterapia mediante la narración de un caso real que se desarrolla alrededor de la noción de la imagen corporal y la percepción del sujeto consciente.

A través del mismo se descubren elementos fundamentales propios del proceso arteterapéutico, tales como la toma de contacto, la creación del vínculo terapéutico, el papel de las producciones artísticas como vehículos de la comunicación o la importancia del cierre del proceso.

En la narración se emplea a menudo la primera persona no sólo con la finalidad de acercar el proceso terapéutico a través de la visión personal del arteterapeuta, sino también con la idea de evidenciar que es necesario establecer una actitud responsiva en su desarrollo, debido tanto a las circunstancias del entorno que van surgiendo como al feedback del mismo paciente durante su evolución.

\section{Antecedentes}

Uno de los conceptos que afloran de forma recurrente durante el trayecto arteterapéutico, es el de la imagen corporal, esto es, la construcción que cada individuo hace de su propia imagen y su proyección en el exterior.

Según las tesis de Dolto, la imagen del cuerpo se elabora en la historia misma del sujeto y es por tanto susceptible de modificaciones a lo largo de la existencia (Dolto, 1984). La construcción de esta imagen comienza en las etapas tempranas de crecimiento de la persona. Esta construcción inicial se constituye mediante tres representaciones de la imagen de uno mismo. Dolto las define como la imagen de base, la imagen funcional y la imagen erógena. Todas juntas impri- 
men y otorgan al ser humano la noción holística de su propia imagen corporal, es decir, confieren al narcisismo su razón de ser.

La imagen de base es la imagen inicial en la formación de la imagen corporal. Viene determinada por las primeras percepciones sensoriales y los reflejos primarios que experimenta el bebé. Esta primera imagen permite desarrollar el tejido necesario para la creación del narcisismo primario de donde procedería la noción de existencia, de ser en el mundo.

Esta imagen de base se va construyendo en diferentes etapas ligadas entre sí, si existe lo que Dolto denomina una buena arquitectura relacional que las mantenga cohesionadas y que dependería casi siempre del acompañamiento de una buena madre nutricia a través de las palabras y de la caricia.

Otra componente de la imagen del cuerpo es la imagen funcional, que permite localizar en el esquema corporal cómo satisfacer una demanda que tiene por origen el deseo (por contraposición a la necesidad vital). Por ejemplo, el chupeteo en el bebé en contraposición con el llanto por hambre.

Asimismo la imagen erógena del cuerpo, asociada a determinada imagen funcional del mismo, sería aquella donde se focalizarían el placer o el displacer erótico en relación con uno mismo o con el otro.

Así poco a poco, a través del sentimiento de un ser humano que se amarra a su cuerpo intentando crearse una convicción ilusoria de continuidad y unidad, se iría constituyendo el inicio del narcisismo. Cuando este sentimiento de continuidad falla, pueden producirse desórdenes, desarreglos o conflictos que cabe interpretar como auténticas "caídas" o "fallas de narcisismo", y que pueden llegar a producir en un futuro graves consecuencias, sobre todo durante el curso del desarrollo edípico, en el que pueden emerger algunos síntomas que quizás no aparecieron en la infancia, dando lugar en el niño a una regresión hacia los estadios más tempranos de su evolución.

Por otra parte, es importante distinguir claramente el concepto de imagen del cuerpo con el del esquema corporal, entendido este último como el que especifica al individuo en cuanto a representante de la especie y que actúa como el intérprete de la imagen del cuerpo, a veces invalidado por la construcción de una imagen perturbada.

El caso que se expone a continuación presenta un joven de 21 años con una pobrísima construcción narcisista de base, que de manera súbita se ve agravada por un problema real inscrito dentro de su esquema corporal; un accidente que le acompañará a lo largo de su vida.

\section{Anamnesis del caso}

Este joven, al que a partir de ahora denominaremos $\mathrm{O}$, llega al centro donde trabajo como arteterapeuta para realizar un tratamiento de su adicción a las drogas. Parece que ya desde niño, y a pesar de que se recuerda como un muy buen chico, tuvo serios problemas de conducta y de relación, habiendo precisado desde los 12 años de la ayuda de profesionales, que le diagnosticaron hiperactividad. 
Tiene un padre que de pequeño él vive como ausente a consecuencia de su trabajo, una madre sobreprotectora y dos hermanos mayores, un chico y una chica. Parece que esta última sufrió de anorexia durante su adolescencia, a pesar de lo cual es la que más ha cumplido con las perspectivas familiares, ya que su hermano mayor ha tenido también problemas con las drogas.

Desde niño siempre quiso emular algunas de las acciones que realizaban los mayores, lo que le ocasionó serios problemas en su adolescencia y dificultades en la escuela, en la que era castigado continuamente por su falta de puntualidad y por mala conducta. Empezó entonces a "hacer campana" y a deambular por las calles en su horario escolar.

En uno de esos días se "dejó enganchar", según sus palabras, por un chico mayor que él, que lo introdujo en el mundo de las drogas, y que aprovechándose de su ingenuidad le sacaba el dinero que robaba a su familia, al principio en cantidades pequeñas, que fueron aumentando poco a poco, hasta llegar al robo de joyas.

Empezó con el consumo de porros y, poco a poco, fue probando todo tipo de sustancias. Su rendimiento escolar empeoraba día a día, tenía problemas con los profesores y con otros alumnos hasta que lo expulsaron de la escuela. Adoptó entonces una estética skin para vivir la experiencia de pertenencia a un grupo a pesar de lo cual esta nunca se dio. Al descubrir sus que padres que $\mathrm{O}$ les estaba robando lo echaron de casa, pero lo acogieron de nuevo al comprobar que no se arrepentía ni regresaba en busca de su protección. Cuenta que por aquella época solo tenía un amigo y que este lo abandonó cuando se dio cuenta de las malas influencias que lo rodeaban. O estaba cada día más solo.

$\mathrm{Su}$ entorno relacional lo era tan solo con un grupo de moteros con los que realizó algunas fechorías circulando a gran velocidad después de importantes consumos, poniendo continuamente su vida y la de los demás en peligro. A los 16 años, en una de esas noches de consumo exagerado, colisionó su moto contra un camión de la basura. Una semana más tarde se despertó en la UCI de un hospital donde había estado varios días en coma. Nadie le dijo que le habían amputado la pierna derecha. Se dio cuenta de ello cuando lo trasladaron de la cama a una camilla. Una noche quiso levantarse medio dormido y se cayó al suelo. Todavía no tenia conciencia de lo que le había sucedido.

Después del accidente la situación se agravó, el consumo de drogas no cesó de aumentar y realizó varios cambios de escuela, pero, dada su situación, acabó dejando los estudios, hasta que poco a poco la situación fue insostenible y sus padres decidieron ingresarlo en un centro de desintoxicación.

\section{Encuadre arteterapéutico y objetivos}

$\mathrm{Mi}$ acompañamiento de $\mathrm{O}$ se produce dentro de una institución que se encarga de tratar su adicción a las drogas y que realiza con los pacientes un trabajo terapéutico educativo de tipo cognitivo-conductual, a partir de lo que se denomina la fuerza del grupo. 
Se trata de una institución de carácter privado en la que los pacientes suelen permanecer ingresados una media de 60-70 días, tras los cuales algunos marchan con sus familias a su lugar de origen y otros permanecen cercanos al centro en pisos o casas tuteladas durante un período más o menos largo, en dependencia de su evolución. Unos y otros siguen adscritos al programa para su seguimiento con una pauta regular de asistencia a terapia y con el deber de cumplir los timing que les vienen propuestos desde el equipo terapéutico.

Durante el período de ingreso, el arteterapia está contemplada como un recurso más dentro del tratamiento, llevándose a cabo una sesión semanal con todo el grupo de ingresados, que suele oscilar entre 15 y 20 personas. Además se cuenta con dos pequeños grupos de 6 personas cada uno, en sesiones a las que denominamos Arteterapia de Expresión Emocional (en adelante AEE) y de los que participan aquellos pacientes que el equipo entiende puedan ser más susceptibles de beneficiarse de un trabajo de estas características. Todas estas sesiones, unas y otras, tiene una duración de 135 minutos, con 15 minutos de descanso.

Para realizar las sesiones de arteterapia con el grupo de pacientes ingresados contamos con una sala de grandes dimensiones mientras que trabajamos en una sala mucho más reducida para realizar las sesiones de AEE en las que pueden participar a la vez pacientes en fase de ingreso junto con otros pacientes en fase de seguimiento.

Como se ha mencionado anteriormente el trabajo con el arteterapia durante el período de ingreso suele oscilar entre un par de meses o algo más. En cambio el trabajo en lo grupos de AEE puede llegar a prolongarse durante parte del seguimiento con una duración media de nueve a doce meses. Cada cierre se consensúa a través de una puesta en común entre todos los profesionales del equipo, en dependencia de la evolución del paciente, para dar paso a una nueva incorporación.

En ambos tipos de grupo las sesiones tienen tres fases: una primera fase de calentamiento, donde hablamos un poco de como han transcurrido la semana y realizamos algún tipo de ejercicio para preparar la matriz grupal; una segunda fase de creación, a veces a través de una consigna común, otras veces a partir de materiales, y muy a menudo libremente partiendo de las circunstancias personales que rodean a cada paciente; y una tercera fase de participación y puesta en común del trabajo realizado.

Desde la posición de arteterapeuta, mi primer objetivo consiste en construir para los pacientes un espacio diferenciado del resto de las terapias habituales, atendiendo y adaptándome a aquellas circunstancias que emergen en cada momento.

En este sentido, mi atención no debe ser tanto respecto a aquello que presumiblemente les une (la adicción) sino justamente sobre lo que les diferencia, tratando así de respetar las individualidades, fomentar su autonomía y desarrollar su subjetividad. 
En segundo lugar, trato de que los pacientes puedan desarrollar su potencial de creación a través del uso de diferentes lenguajes artísticos mediante los cuales puedan depositar y otorgar significados emocionales.

Finalmente deberé tratar con especial atención el vínculo y la distancia terapéutica adecuados para que pueda darse una buena integración del trabajo realizado que favorezca un proceso de cambio.

Para lograr estos objetivos es conveniente mantener una actitud de acogida y respeto a la sintomatología de cada paciente a la espera de los resultados del proceso.

\section{Toma de contacto e incorporación al taller de arteterapia.}

El primer día que el equipo me habla de $\mathrm{O}$ no llego a conocerlo. A la hora prevista para la sesión de arteterapia decide no bajar de la habitación. Parece que desde que ha ingresado sólo habla de irse a consumir. No quiere comer. No quiere estar allí. Finalmente se va de alta voluntaria, pero regresa nuevamente al centro acompañado de sus padres pasados 3 días.

Me comentan que a pesar de su vuelta sigue sin adaptarse, no va a las actividades y, si lo hace, hay que ir a buscarlo a la habitación. Se aísla del grupo, no se asea, muestra conductas desdeñosas y pasivamente provocativas. A menudo se expresa a través de un lenguaje algo paranoide, poco audible e incomprensible, que algunos miembros del equipo ven como simulado para llamar la atención. Habla de suicidios, asesinatos y agresiones crueles que desearía llevar a cabo de manera morbosa. Se lleva algún cuchillo del comedor, que esconde de forma muy evidente en su habitación, como si quisiera ser descubierto. Algunas veces grita y golpea las paredes utilizando expresiones como "te juro que te mato" y otras similares. Cuando algún miembro del equipo acude en su ayuda para comprobar que está pasando, lanza frases amenazantes del tipo "yo de vosotros cerraría la puerta con llave".

Finalmente lo conozco durante la siguiente semana. No está presente en el inicio de la sesión. Parece que se duerme y llega tarde a todas las actividades. Aviso de su ausencia y llega unos minutos más tarde. Mi primera visión de él es la un chico-niño desamparado, con una sola pierna, sentado en una silla de ruedas, recién levantado, sin asear, con una mueca de asco en su cara, que no me mira a los ojos y que apenas articula algunas palabras en un bajísimo tono de voz, sin importarle si puedo o no entenderlo.

En el momento de su incorporación al trabajo estamos realizando unos ejercicios de contacto por parejas. Observo al grupo y me doy cuenta de que $\mathrm{O}$ no es demasiado bien aceptado. Presiento que existe un cierto rechazo a trabajar con él. Antes de que sea demasiado obvio asumo esa responsabilidad y me dispongo a acogerlo y a ser su pareja. Tengo miedo de su reacción, pero curiosamente acepta de muy buen grado el contacto. Nos masajeamos la espalda el uno al otro y después realizamos juegos de confianza, junto con el resto del grupo. Cierra sus ojos y se deja llevar por mí de la mano, él en su silla de ruedas y yo a un costado, cuidándole. Después yo cierro mis ojos y él me lleva de la mano por toda la sala 
tratando de evitar que me golpee o me choque con alguien. Al acabar, todas las parejas se dan las gracias y nosotros también. Presiento que vamos a poder trabajar juntos. En el tiempo de creación donde trabajamos una consigna conjunta se muestra muy concentrado. Parece que le gusta dibujar. Realizamos el cierre y, al acabar, me despido de él hasta la semana próxima.

Semanalmente los miembros del equipo realizamos una sesión para hablar de la evolución de los pacientes e intercambiamos nuestros puntos de vista. Los comentarios sobre $\mathrm{O}$ que recibo antes de cada sesión suelen ser muy negativos, pero en cambio, en el transcurrir de las semanas no tengo ningún tipo de problema con él, por el contrario siempre participa con gusto de los ejercicios de interrelación grupal, donde poco a poco va siendo más aceptado por algunos compañeros. A la vez se muestra muy implicado en los tiempos de trabajo creativo, que habitualmente participa al resto del grupo. Observo que poco a poco y en el transcurrir de los días las facciones de su rostro se dulcifican y se asemejan más a las de un niño, pero los problemas persisten.

Algunas veces siento una cierta inseguridad respecto de algunas propuestas que realizo, al pensar si se sentirá perturbado por su discapacidad, pero a pesar de ello suelo arriesgarme y siempre responde sin problemas, devolviéndome así algo de mis propios miedos.

Durante este tiempo le han construido una prótesis que debe empezar a usar progresivamente hasta su definitiva adaptación. Parece que tiene dificultades para colocársela y además le produce mucho dolor. Es necesario que el muñón se vaya adaptando y para ello debe usarla por lo menos algunas horas al día hasta que se acostumbre, pero $\mathrm{O}$ sigue prefiriendo la silla de ruedas con la que se desplaza más fácilmente, y este conflicto le acarreará algunos problemas.

La problemática suscitada con la prótesis que debe llevar muy a pesar suyo, hace que durante su participación en las sesiones de grupo $\mathrm{O}$ vaya sustituyendo el discurso paranoico/aberrante que sigue manifestando algunas veces, por una actitud provocadora que le lleva a flexionar ostentosamente y en todas direcciones la mecánica de su prótesis o a golpearla rítmicamente de forma in crescendo, quejándose en voz alta y haciendo bailar nerviosamente las ruedas de su silla. Toda una sinfonía de ruidos que consigue captar la atención y desconcentrar al grupo, que finalmente la mayoría de las veces acaba por mostrar una actitud hostil hacia él. Siento que sólo quiere que le escuchen; hacer notar su presencia; que sepan que le duele. Trato de prestarle una cierta atención sin desatender al resto, pero las relaciones de $\mathrm{O}$ con el grupo se van deteriorando.

\section{Transición hacia las sesiones de AEE}

En las reuniones de equipo sigo escuchando quejas constantes sobre su comportamiento y sobre su incumplimiento de horarios y normas, llegándose a comentar la posibilidad de expulsarlo del centro si no modifica su actitud.

Defiendo fehacientemente la necesidad de que siga allí y de que se entre a profundizar sobre las dificultades añadidas que puede representar para el centro 
un caso como este, sobre cuyas características no debe prevalecer unicamente el tratamiento de su adicción sino todo lo que conlleva la amputación de una pierna tratándose además de un chico tan joven.

Parece que mi discurso ha sido considerado, y finalmente se ha decidido darle otra oportunidad precipitando un alta para que pueda volver a su casa e iniciar desde allí la fase de seguimiento en la que deberá venir al centro cada día para seguir sus terapias.

Pido al equipo poder seguir el trabajo con $\mathrm{O}$ en las sesiones de AEE (grupos de seis personas un par de veces por semana). Se acuerda que así será.

\section{Seguimiento en las sesiones de AEE}

Se muestra contento de poder participar de estas sesiones y le sienta bien el trabajo en un grupo pequeño, donde además la mayoría de participantes son jóvenes como él. Sé que le gusta pintar y parece que se siente muy bien haciéndolo. En su época de consumo había pintado en las paredes de la calle. Por ahora dejo que trabaje a su ritmo, en libertad y $\mathrm{O}$ se especializa en pequeños graffitti, que acaba regalando a todas los miembros del equipo para mostrar su agradecimiento, y que según mi parecer actúan como producciones intermediarias entre él y los demás, dada su dificultad con la palabra por el momento. Quiere agradarnos. Es como si por un lado tratará de pedir disculpas por sus dificultades y por el otro tratará de hacerse entender. ()

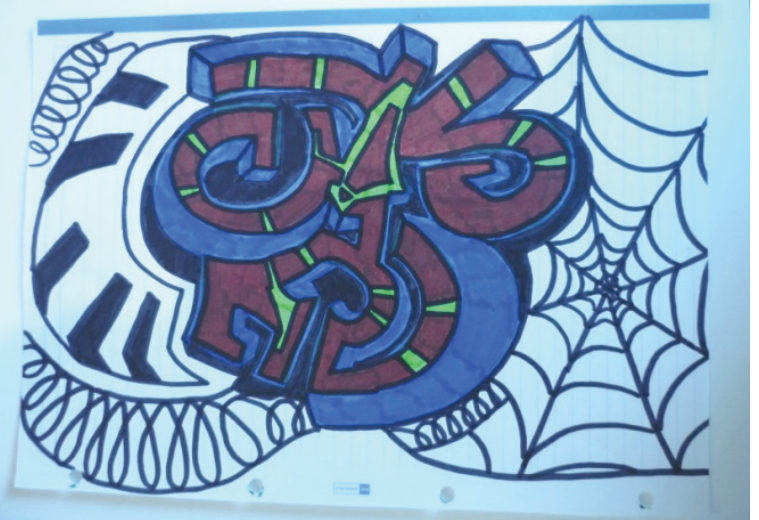

Fig. 1. Graffiti de O

No obstante a los pocos días de su vuelta a casa empiezan los problemas, $\mathrm{O}$ no puede levantarse de la cama para afrontar el día a día y las pequeñas responsabilidades que se le han pautado. Sus padres se ven superados, piden continuamente ayuda a sus terapeutas y, como consecuencia de esta situación, se decide apartarlo de su casa, y llevarlo a compartir piso con otros cuatro pacientes tutelados cerca del centro, con

la idea de que aprenda a responsabilizarse más de si mismo.

Esta decisión tampoco funciona ya que no se relaciona bien con el resto de compañeros. La convivencia no es buena. Se siente mal. Le piden lo mismo que se piden a ellos, y él no puede darlo. Es obvio que su problemática es mayor. No se siente querido ni comprendido. Echa de menos su casa y a su madre, elemento cuidador muy importante que hasta ahora le ha venido solucionando todos los 
problemas. Siente mucha añoranza y se muestra a los ojos de los demás como un bebé abandonado. Quiere levantarse de la cama para afrontar el nuevo día, pero, según sus palabras, hay algo superior a él que se lo impide, de manera que sigue sin poder asumir las responsabilidades que le pautan sus terapeutas, como consecuencia de lo cual se ve sometido a mucha presión por parte de éstos.

En las sesiones parece desahogarse a través de la pintura. Sigue adelante con los graffittis y fuera de estos casi todas sus producciones son muy estereotipadas, con eslóganes antidroga y referencias a un mundo idealizado que presumen muchos adictos por el hecho de abandonar sus consumos.

No obstante, sólo habla si se le pregunta. De lo contrario se mantiene en silencio, baja la cabeza a la altura de la mesa creando alrededor suyo una especie de burbuja protectora que parece mantenerle aislado. Sin embargo, me doy cuenta de que mantiene una escucha más abierta de lo que pudiera parecer a simple vista. Finalmente, si yo le pregunto, y tras una primera negación,

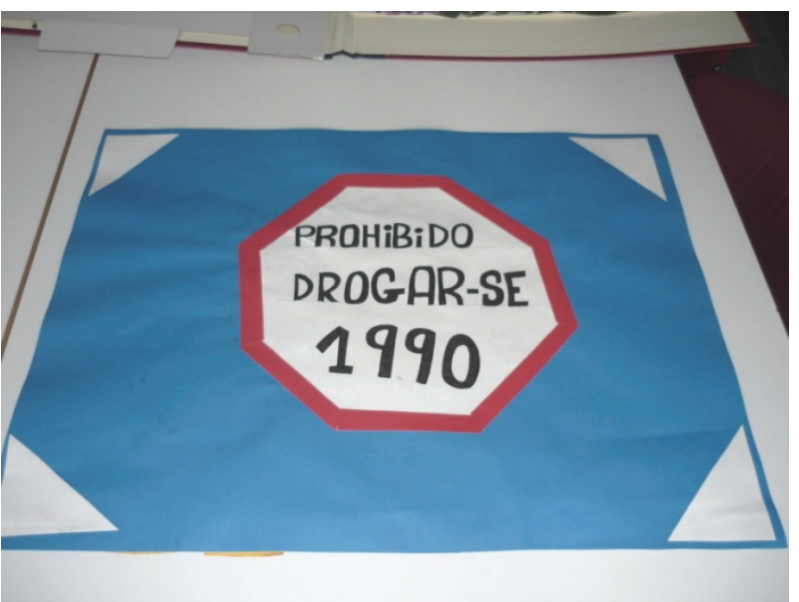

Fig. 2. Eslógan anti-droga suele responder a mis palabras y casi siempre acaba manifestando su culpabilidad por no poder estar a la altura de lo que se le pide. En el transcurrir de los días y de manera progresiva, va entrando en un estado depresivo que trato de comprender y transmitir a sus terapeutas en un afán de acompañarlo y recoger su problemática. Creo que cada día es un poco más consciente de su discapacidad, aunque él sólo habla de su adicción. Algunas veces nos habla del síndrome del miembro fantasma, bastante común en las personas amputadas, y nos comenta que siente dolor en su pierna desaparecida o que sueña respecto de no haberla perdido. Otras veces nos comenta que es al ir al lavabo cuando se da cuenta de que carece de una de sus extremidades inferiores. Últimamente está padeciendo arcadas, sobre todo cuando piensa en su pierna faltante a la que se refiere como "ésta". Pero estos comentarios suelen ser excepcionales y casi siempre sin entrar a profundizar demasiado en el tema, que siempre acaba llevando al terreno de su adicción y a las secuelas que ésta ha dejado en su forma de actuar. Mantiene un discurso conformista en el que, según él, todo son "ganas de consumir".

Finalmente, dado que la decisión de que compartiera piso con otros pacientes no ha dado resultado y considerando que a pesar del intenso acompañamiento 
terapéutico que recibe, está cada día más triste y más abandonado a su suerte, el equipo decide que vuelva a casa y que siga viniendo a las terapias y actividades desde allí. A pesar de todo, persistirán sus problemas para levantarse.

Su participación en las sesiones de AEE sigue adelante y los graffittis evolucionan hacía otras producciones plásticas de carácter un tanto infantil que va alternando con la escritura, esta última muy pura, tanto en la forma como en el contenido. Suele entrar a las sesiones cabizbajo y sin mirar a la cara, pero a medida que transcurren la mismas se va relajando y participa sobretodo en el tiempo de puesta en común de las producciones.

Poco a poco empieza a inspirarse en otros motivos para pintar. A partir de ahora la mayoría de sus producciones empiezan en una dirección y acaban evolucionando hacia otros lugares a través de la superposición de capas.

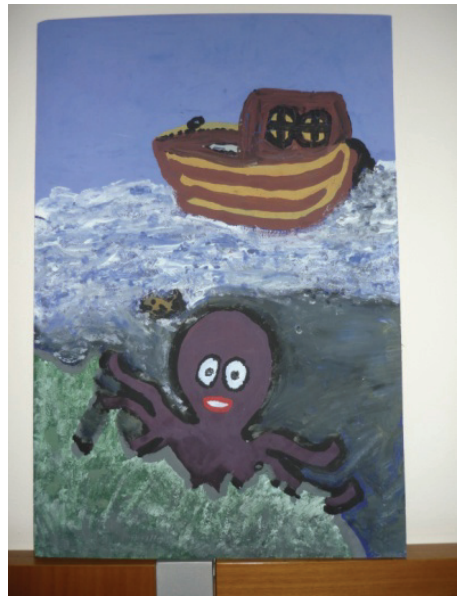

Fig. 3. Ilustración del pulpo

Da pocas explicaciones sobre lo que hace. Trabaja lenta y minuciosamente, pudiendo permanecer concentrado y en silencio durante mucho rato. Sus obras suelen estar sobrecargadas de elementos y de material, como si necesitara vomitar sobre ellas todo lo que no quiere o no puede hablar y va modificándolas de sesión en sesión sobre un mismo soporte.

De vez en cuando deja alguna frase o dibujo a lápiz o bolígrafo sobre papel en blanco; sencillas producciones que suelen pasar inadvertidas hasta el momento de la recogida, cuando emergen a modo de pequeño mensaje que $\mathrm{O}$ va dejando entre producción y producción junto con algunos artículos recortados de revistas que guarda en su carpeta.

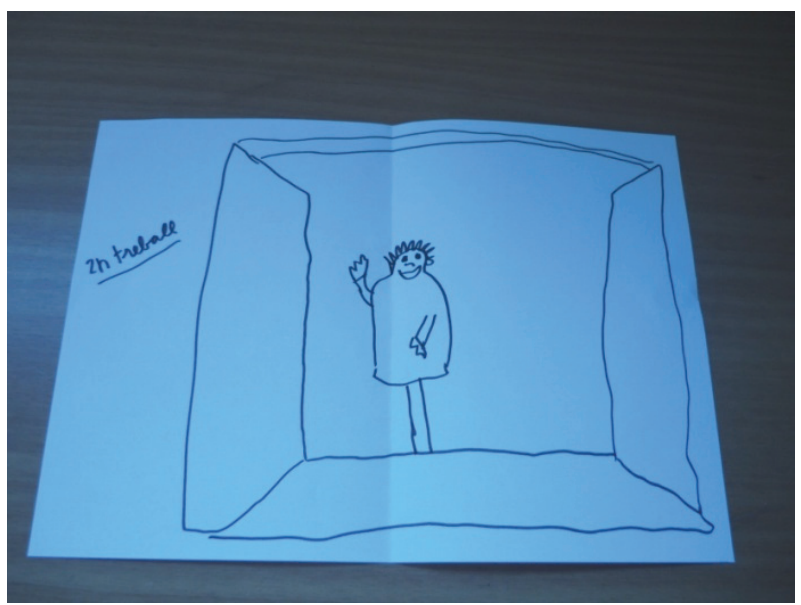

Durante este tiempo sucede un hecho muy importante. De manera inesperada su madre enferma gravemente $y$ muere en un corto período de tiempo. O debe afrontar ahora esta importantísima pérdida, que se suma a multitud de pérdidas anteriores. Sabe del pronóstico de su madre, aunque no quiere hablar

Fig. 4. Dibujo a bolígrafo 
de ello. No obstante, en una de las sesiones, pinta un cuadro para ella con una carta en su reverso que le entregará pocos días antes de su muerte. Lo siento muy perdido, más si cabe, no sabe cómo actuar, qué debe hacer ni cómo puede realizar el duelo. Nos quiere leer la carta que le ha escrito a modo de despedida, y por primera vez rompe a llorar desconsoladamente mientras lo hace.

Seguimos adelante trato de ir reforzando el vínculo que estamos creando para poder acompañarlo en estos momentos tan difíciles y de crear para él un espacio diferenciado, donde no exista presión, donde pueda sentirse protegido y pueda madurar y evolucionar por sí mismo a través de su proceso de creación. Me planteo la posibilidad de que paralelamente a la elaboración del duelo por su madre pueda ir elaborando el duelo por su pierna, algo suyo, propio, que parece pasar desapercibido para la mayoría de personas que le rodean. De la misma manera, queda pendiente también elaborar el duelo por las drogas, que ahora no pueden mitigar su dolor como lo habían venido haciendo durante muchos años.

Cuando su mamá fallece $\mathrm{O}$ trae de nuevo la pintura que le había regalado y pinta sobre ella una pequeña casita con un camino. Dice que se trata del camino que conduce al cementerio donde ella estará a partir de ahora.

Lentamente y con muchos baches va pudiendo hablar cada vez un poco más de sus preocupaciones, habla de si a través de sus producciones a las que puede empezar a otorgar un significado a la par que va fortaleciendo el vínculo conmigo y con sus compañeros de grupo.

Aunque hemos hablado repetidamente de la importancia del vínculo terapéutico para que un proceso de acompañamiento pueda fructificar, las producciones en arteterapia son el recurso que media más a menudo entre el paciente y el arteterapeuta. La lectura del trabajo creativo con las producciones tiene para mí muchas acepciones. Puede indicar por ejemplo la falta o el exceso de palabras, una ofrenda de afecto, un vómito agresivo, una metáfora o un símbolo del conflicto a desanudar, un elemento asegurador, una amenaza para el paciente o para el arteterapeuta, una apertura o a veces un cierre de la comunicación, la evidencia de una frustración, una defensa yoica, la emergencia de algo nuevo, desconocido $\mathrm{y}$ fascinante, $\mathrm{y}$, también a veces, la aparición de una pequeña obra de arte capaz de sublimar algunos aspectos del conflicto en la persona.

Si sabemos realizar una buena lectura de las producciones, éstas pueden darnos información y evidencias sobre nuestros pacientes; nos remiten a su historia, orientándonos así hacia una dirección del trabajo, permitiéndonos a la vez rodear mejor sus resistencias y poder realizar un mejor acompañamiento de sus conflictos.

En el trabajo con O esperaba que él pudiera depositar en ellas significados emocionales a sus conflictos que no era capaz de verbalizar y creo que así lo hizo. $\mathrm{O}$ se relacionaba a través de ellas, se autorizaba a hablar al compartir sus trabajos con el grupo y expresaba sus deseos y sus dificultades en sus dibujos y sus textos.

\section{Cierre}


Han pasado 13 meses desde el ingreso de $\mathrm{O}$ y debe pasar a otra fase del tratamiento.

Cuando le anunció el próximo cierre de las sesiones parece entristecerse. El último día recoge sus producciones y agradece al grupo el trato que ha recibido a través de una producción que representa un símbolo de la paz. Me obsequia con un nuevo graffiti con mi nombre. Siento que esta despedida, aunque prematura, le permite tener una pequeña experiencia de duelo, tan necesaria para él.

Me pregunta antes de irse si creo que puede mejorar en la pintura y se emociona al recibir una sencilla caja de rotuladores que un compañero le regala, diciéndole "la vi en una tienda de chinos y pensé en ti" Queda bloqueado, no sabe que decir y finalmente, emocionado, comenta "es el primer regalo que recibo de alguien de fuera de mi familia" Entonces pienso en lo necesario que es para el sentirse apegado a algo, sentirse existir, y el detalle de su compañero lo ha conseguido.

\section{Conclusiones}

El método arteterapéutico dirige su atención a traspasar la concepción clínica de la enfermedad a través de la escucha y el acompañamiento de la experiencia particular de cada individuo. Se trata pues, de una metodología que invita a la personalización de cada proceso terapéutico y en el caso de $\mathrm{O}$ creo que era imprescindible atender a su particularidad específica, más allá de su adicción.

Por su historial, y a través de mi experiencia con él, he construido mis propias hipótesis.

Posiblemente $\mathrm{O}$ tuvo ya desde su infancia dificultades importantes en el desarrollo de su personalidad. Para sobreponerse a estas dificultades descubrió un estado de sedación a través del consumo de estupefacientes, que le llenaba un cierto vacío y le hacía sobrellevar sus problemas. Esto sucedió en plena organización edípica de su persona impidiendo su desarrollo madurativo y dejándolo atrapado en etapas infantiles anteriores, con el hándicap añadido de que ahora esta dificultad se había visto doblemente agravada por la pérdida de su pierna, que afectó si cabe aún más, a la ya de por si maltrecha construcción de su imagen, que recibe una fuerte agresión en el esquema corporal sobre el que $\mathrm{O}$ se proyectaba.

Desde un inicio traté de trabajar de manera sutil y cuidadosa algún tipo de contacto cuerpo a cuerpo. Algunas personas pueden pensar que quizás es un trabajo demasiado cercano a su problemática, pero la fuerza de lo real en este caso, me hizo pensar que debía acompañar esa situación a través del contacto, para que $\mathrm{O}$ pudiera vivir este nuevo cuerpo como el mediador entre él y el mundo. Y había que conseguir que pudiera hacerlo.

Por otra parte, había que trabajar esa dificultad suya con el despertar: el levantarse de la cama. Pensaba que hace tiempo O se levantó de su cama en la UCI y descubrió que no se sujetaba de pie. Quizás cada vez que realizaba esta acción se le pudiera estar presentando la repetición de algo ya vivido que no acaba de querer reconocerse como real. Había que seguir trabajando para que fuera tomando conciencia de su situación y aprendiera a reconciliarse con ella. Quizás en 
la cama se protegía no tanto de su discapacidad, sino de su incapacidad para tolerar los retos y los fracasos que la maduración y la vida le estaban imponiendo, algunos de forma muy cruel. Pensé también en el triunfo de las pulsiones de muerte sobre su persona, siempre tan desmotivada y deprimida, dejando descansar un cuerpo que al dormir, como anónimo, descansa de las exigencias del sujeto, y creí entender que no pudiera despertarse ni quisiera levantarse de la cama.

Intenté también trabajar su introversión, su imposibilidad de comunicar, y traté de leer en sus actos y en sus producciones lo que no podía escuchar a través de sus palabras.

A diferencia de las exigencias a las que era sometido habitualmente dentro del tratamiento, traté de acoger sus dificultades, entenderlo y tratar de ayudarlo a hablar, no del por qué, sino del cómo se sentía.

El trabajo con el cuerpo y con la creación que vino realizando desde su ingreso, permitieron ordenar y estructurar algo de si mismo que pudo ayudarle a construir o reconstruir su propia imagen, actualizándola y a una nueva proyección de la misma en el exterior.

El sentimiento de pertenencia a un grupo que $\mathrm{O}$ no había sentido en ningún momento durante su infancia y su juventud, ayudó a devolverle una imagen de si que había perdido por partida doble como consecuencia del accidente o que quizás nunca llegó a conseguir.

Los intercambios verbales alrededor de su obra y el trabajo con la materia le permitieron disponer de un soporte para salir de su pequeño delirio y encontrar un pequeño orden simbólico para el desorden que produce el sufrimiento.

La atención y el cuidado prestado a la forma en que se desarrolló el vínculo terapéutico pudo generar en $\mathrm{O}$ una vivencia de continuidad que le permitió seguir adelante.

Se trataba en definitiva de crear las condiciones para poder abordar la "vivencia integradora de su desarrollo emociona", según lo describe Miquel Izuel (2012).

Creo que $\mathrm{O}$ ha sobrevivido a una fase muy importante de su vida pero es necesario y urgente que siga construyendo para si una identidad, una imagen de si mismo con la suficiente entidad para sostener y aceptar su discapacidad, su falta.

Después de finalizar las sesiones de AEE, O realizó clases de pintura en una escuela para mejorar su técnica hasta que más adelante, orientado por sus terapeutas, lo dejó para poder obtener el graduado. Actualmente esta cercano a cumplir los 23 años. Dice no saber todavía qué quiere estudiar en un futuro, se debate entre algo relacionado con la naturaleza, ser terapeuta o tomar el camino del diseño gráfico. Tiene una nueva prótesis que le permite realizar un poco de ejercicio, y por lo demás, sigue acudiendo regularmente a sus terapias de drogadicción. De momento su mayor identificación lo es como "adicto en recuperación", lo que le permite ayudarse a seguir adelante. Por ahora parece rechazar reconocerse con otro colectivo que pueda devolverle una imagen de si mismo que le haga sentir mal, pero siento que puede ir encontrando nuevas oportunidades para crecer. 
Es un chico tímido que a veces me parece triste. Esa timidez le impide visitarme algunas veces, cuando vuelve al centro. Se pone muy rojo cuando le digo que me gusta mucho volver a verlo y hablar con él, pero acepta gustoso que le convoque y ha accedido a ayudarme en algunos puntos de esta presentación.

Es necesario mantener en él su deseo de ser, para evitar, que como dice Dolto, "anulado el lugar de la falta y de su expresión por el grito, el niño deja de alertar a su madre con sus llamadas y, poco a poco, acaba no esperando ya nada de la presencia del otro".

\section{Referencias bibliográficas}

DOLTO, F. (1984). La imagen inconsciente del cuerpo. Ed.Paidós

WINNICOTT DONAL W. (1993) Los procesos de maduración y el ambiente facilitador. Ed. Paidós

GUIMÓN, J. (1999) Los lugares del cuerpo. Ed.Paidós

DOMÍNGUEZ, P. M. (2004). Arteterapia. Principios y ámbitos de aplicación. Sevilla

IZUEL, M. (2012) Arteterapia, el porvenir de una ilusión. 